Dr Dragoljub M. Brkić,

dipl. inž

Tehnički opitni centar KoV,

\section{JEDAN POSTUPAK PODELE KOEFICIJENTA NAUČNO-STRUČNE KOMPETENTNOSTI UČESNICIMA NA ZADATKU}

UDC: $355 / 359-051: 519.233 .6$

Rezime:

U ovom radu izložen je jedan postupak podele koeficijenta naučno-stručne kompetentnosti učesnicima na obavljenom zadatku. Postupak je zasnovan na rangiranju učesnika prema njihovom doprinosu izvršenju zadatka. Radi preciznije procene udela na zadatku usvojeno je da rang učesnika može da bude ne samo ceo broj, nego i decimalni broj, a uveden je i koeficijent uskladenosti veličine učešća $i$ dodeljenog ranga učesnicima na realizaciji zadatka. Pomoću matematičkog modela vrši se transformacija dodeljenog ranga učesnika u težinski koeficijent učešća. Razvijen je i specijalni računarski program koji je korišćen za rešavanje problema ove vrste. Primena ovog postupka ilustrovana je na jednom praktičnom primeru.

Ključne reči: koeficijent naučno-stručne kompetentnosti, učesnik na zadatku, rang učesnika na zadatku, koeficijent usklađenosti veličine učešća i dodeljenog ranga učesnicima na realizaciji zadatka, težinski koeficijent učešća na zadatku.

\title{
ONE METHOD FOR ASSIGNING SCIENTIFIC-PROFESSIONAL COMPETENCY COEFFICIENTS TO PARTICIPANTS IN THE WORK
}

\section{Summary:}

In this paper one method for assigning scientific-professional competency coefficients to participants in the work is presented. This method is based on the ranking of participants in accordance with their contribution to the work. In order to make a better assessment of the contribution to the work, it is assumed that a rank can be not only an integer, but also a decimal number, and the compatibility coefficient is also introduced. By using a mathematical model, the transformation of the ranks into the weight factors of participations was made. Fot this purpose, a special computer program was developped and used in solving problems of this kind. Application of this method is illustrated by one practical example.

Key words: scientific-professional competency coefficient, participant in the work, rank of the participant in the work, compatibility coefficient of participation and assigned rank, weight factor of participation in the work.

\section{Uvod}

U institucijama, kao što je Tehnički opitni centar (TOC KoV), na izvršavanju nekog zadatka obično se angažuje veći broj izvršilaca - nosilac zadatka, njegov zamenik i veći broj drugih učesnika. Među učesnike mogu se ubrojati i rukovodioci koji daju saglasnost i oni koji overavaju završeni zadatak.
Za završeni zadatak dodeljuje se koeficijent naučno-stručne kompetentnosti $R$ prema [2]. Zavisno od toga o kojem se izlaznom dokumentu o završenom zadatku radi (izveštaj, elaborat ili standard), stručni kolegijum, koji verifikuje završeni zadatak, koriguje dodeljeni koeficijenat naučno-stručne kompetentnosti iz [2]. Ta korekcija se obavlja prema [1]. Posle izvršene korekcije koeficijenta naučno- 
stručne kompetentnosti, $R$, potrebno je izvršiti njegovu podelu učesnicima na završenom zadatku. Ova podela koeficijenta $R$ učesnicima trebalo bi da bude srazmerna njihovom učešću na izvršenju zadatka. Tako bi se za svakog učesnika procenilo njegovo procentualno učešće na izradi zadatka. Množenjem decimalnog broja koji odgovara procentualnom učešću sa $R$, dobio bi se deo koeficijenta naučno-stručne kompetentnosti koji pripada određenom učesniku:

$R_{i}=\left(p_{i} / 100\right) R$,

gde je:

$R_{i}$ - deo koeficijenta naučno-stručne kompetentnosti $i$-tog učesnika, $p_{i}$ - procentualni udeo $i$-tog učesnika, $R$ - ukupna vrednost koeficijenta naučno-stručne kompetentnosti koja se dodeljuje za završeni i verifikovani zadatak.

Količnik u zagradi gornjeg izraza, $p_{i}$ $/ 100$, može se smatrati težinskim koeficijentom učešća $i$-tog učesnika i obeležiti sa $w_{i}$. Tako bi se deo koeficijenta naučno-stručne kompetentnosti $i$-tog učesnika određivao po formuli $R_{i}=w_{i} R$. Procenjivanje procentualnog učešća pojedinaca u realizaciji zadatka u praksi je prilično teško. Mnogo je pogodnije uvođenje ranga učešća, gde bi učesnici sa nižim rangom imali veći udeo u izvršenju zadatka, nego oni sa višim rangom. Tako bi, na primer, za učesnika sa dodeljenim rangom 1 značilo da je on imao znatno veće učešće od onog učesnika kojem je dodeljen rang 5, i tako dalje. Ovi rangovi primenom određenog matematičkog modela, koji je izložen u teorijskoj osnovi ovog rada, mogu se prevesti u težinske koeficijente učešća $w_{i}$. Određivanje dela koeficijenta naučno-stručne kompetentnosti $R_{i}$ koji pripada $i$-tom učesniku, u ovom slučaju, sprovodi se kao i u slučaju kada je poznat procentualni udeo učešća na izradi zadatka.

\section{Teorijska osnova za rešavanje problema}

Učesnici na nekom zadatku rangiraju se prema njihovom doprinosu datom na izvršenju zadatka. Tako, na primer, rukovodilac radnog tima (grupe) ima rang $r_{1}$, njegov zamenik rang $r_{2} \mathrm{i}$ tako dalje do poslednjeg učesnika na zadatku, koji ima rang $r_{n}(n=1,2, \ldots)$.

Neka je $r_{i}$ rang $i$-tog učesnika na zadatku; $i=1,2, \ldots, n$, gde je $n$ ukupan broj učesnika. Kada se recipročna vrednost ranga $r_{i}$ stepenuje koeficijentom usklađenosti veličine učešća $i$ dodeljenog ranga učesnicima na realizaciji zadatka $K(K \geq 0)$ i nađe zbir svih tako dobijenih članova od 1 do $n$, dobija se:

$S_{n}=\frac{1}{r_{1}^{K}}+\frac{1}{r_{2}{ }^{K}}+\frac{1}{r_{3}{ }^{K}}+\cdots+\frac{1}{r_{n}{ }^{K}}=\sum_{i=1}^{n} \frac{1}{r_{i}{ }^{K}}$

Ako se pojedinačni članovi ovog reda podele sa ukupnim zbirom $S_{n}$, tj. izvrši normiranje (svođenje na jedinični prostor), dobiće se težinski koeficijenti učešća za pojedinačnog učesnika na realizaciji zadatka:

$$
w_{i}=\frac{1}{r_{i}{ }^{K} \cdot S_{n}}=\frac{1}{r_{i}{ }^{K} \sum_{i=1}^{n} \frac{1}{r_{i}{ }^{K}}}
$$

gde je $w_{i}$ težinski koeficijent učešća $i$ tog učesnika na zadatku, tj. učesnika sa rangom $r_{i}$. 
Zbir težišnih koeficijenata učešća jednak je jedinici:

$$
\sum_{i=1}^{n} w_{i}=1
$$

Množenjem leve i desne strane izraza (3) sa koeficijentom naučno-stručne kompetentnosti $R$, dobija se da je:

$$
\sum_{i=1}^{n} w_{i} \cdot R=R
$$

Članovi ovog reda:

$$
R_{i}=w_{i} \cdot R ; \quad i=1,2, \ldots, n
$$

predstavljaju deo koeficijenta naučno-stručne kompetentnosti $R$, koji je dodeljen $i$-tom učesniku čiji je rang $r_{i}$.

Koeficijent $K$ nazvan je koeficijentom usklađenosti doprinosa učesnika koji ima rang $r_{i}$ sa vrednošću $R_{i}$ koja mu je dodeljena $\mathrm{u}$ odnosu na ostale učesnike. Ako se koeficijentu $K$ dodeli vrednost jednaka nuli $(K=0)$, onda se koeficijent naučno-stručne kompetentnosti $R$ podjednako deli na sve učesnike, pa rangiranje u ovom slučaju nema nikakvog efekta. Ukoliko se koeficijentu $K$ dodeljuju veće vrednosti, utoliko se više favorizuju učesnici sa nižim rangovima na račun učesnika sa višim rangovima.

U ovom radu usvojeno je da rang nosioca zadatka bude $r_{1}=1$, a rangovi svih ostalih autora $r_{i}=1,5 ; i=2,3, \ldots, N$, gde je $N$ - ukupan broj autora navedenih $\mathrm{u}$ autorskoj listi. Ako se koeficijent naučno-stručne kompetentnosti deli i na ostale učesnike koji su navedeni u autorskoj listi, onda vrednosti rangova za ostale učesnike su:

$r=5$ - za nadležne koji su dali saglasnost za aktivnosti na zadatku (načelnik laboratorije i načelnik odeljenja), $r=10-$ za načelnika sektora koji je dao saglasnost,

$$
r=15-\text { za zamenika komandanta }
$$

koji overava zadatak i

$r=15-$ za komandanta koji overava zadatak.

U ovom radu usvojeno je da vrednost koeficijenta usklađenosti $K$ bude jednaka jedinici $(K=1)$, što se može smatrati za najadekvatniju vrednost $\mathrm{u}$ slučaju rangiranja učesnika na zadatku. Sve ostale vrednosti za koeficijent $K$ $(K \neq 0 \wedge K \neq 1)$ mogu se smatrati pogodnim za proizvoljno podešavanje raspodele koeficijenta naučno-stručne kompetentnosti $R$ po učesnicima na zadatku.

\section{Praktični primer}

U realizaciji jednog zadatka, čiji je izlazni dokument bio elaborat, bilo je 8 učesnika [3 autora: (nosilac zadatka i dva koautora), 3 učesnika su dali saglasnost i 2 učesnika su izvršili overu završenog zadatka]. Nadležni za ocenu koeficijenta naučno-stručne kompetentnosti, prema smernicama datim u [1], utvrdili su da je polazni koeficijent naučno-stručne kompetentnosti za eleborat $R=6$, a da je njegova vrednost posle korekcije $R=5,1$, gde je u izrazu za korekciju usvojeno da je koeficijent originalnosti $E_{\text {orig }}=1$, koeficijent složenosti $E_{\text {slo }}=0,8$, koeficijent obimnosti $E_{\text {obim }}=0,6$ i koeficijent značajnosti $E_{z n a}=1$ (videti priloženi obrazac za izračunavanje koeficijenta naučno-stručne kompetentnosti).

Potrebno je da se odredi koeficijent naučno-stručne kompetentnosti za sva$\operatorname{kog}$ od ovih 8 učesnika na realizaciji ovog zadatka. 


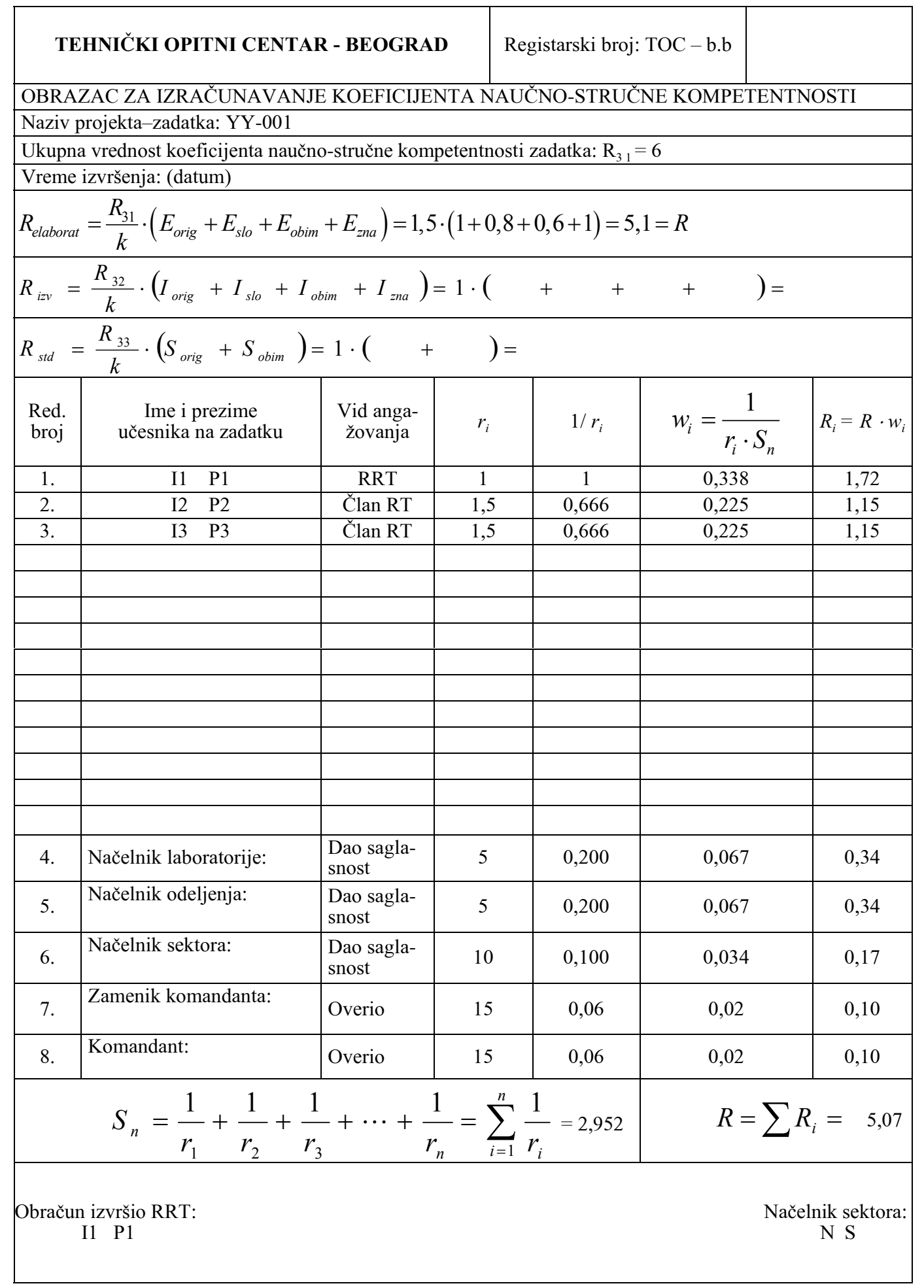




\section{Rešenje:}

Kada se korigovani koeficijent naučno-stručne kompetentnosti $R=5,1$ podeli na 8 učesnika prema postupku opisanom u tački 2; za rangove učesnika $r_{1}=$ $1, r_{2}=1,5, r_{3}=1,5, r_{4}=5, r_{5}=5, r_{6}=10$, $r_{7}=15, r_{8}=15$, i koeficijent usklađenosti $K=1$, dobija se: $R_{1}=1,72$; za prvog učesnika, $R_{2}=1,15$; za drugog učesnika, $R_{3}$ $=1,15$; za trećeg učesnika, $R_{4}=0,34$; za četvrtog učesnika, $R_{5}=0,34$; za petog učesnika, $R_{6}=0,17$; za šestog učesnika, $R_{7}=0,10$; za sedmog učesnika i $R_{8}=$ 0,10 ; za osmog učesnika.

Ako bi se koeficijentu usklađenosti $K$ povećala vrednost tako da je $K=1,5$, za iste vrednosti rangova učesnika, dobilo bi se da je:

$R_{1}=2,19$; za prvog učesnika, $R_{2}=1,19$; za drugog učesnika, $R_{3}=1,19$; za trećeg učesnika, $R_{4}=0,19$; za četvrtog učesnika, $R_{5}=0,19$; za petog učesnika, $R_{6}=$ 0,07 ; za šestog učesnika, $R_{7}=0,03$; za sedmog učesnika i $R_{8}=0,03$; za osmog učesnika.

Ovim bi se više nagradili direktni izvršioci zadatka (rukovodilac radnog tima i članovi radnog tima), a manje oni koji su dali saglasnost i oni koji su overili zadatak.

U priloženom obrascu za izračunavanje koeficijenta naučno-stručne kompetentnosti date su formule koje se odnose na izračunavanje koeficijenta naučnostručne kompetentnosti za elaborat, izveštaj i standard: $R_{\text {elaborat }}, R_{i z v}$ i $R_{\text {std }}$. U ovim formulama figurišu odgovarajući koeficijenti naučno-stručne kompetentnosti $R_{31}$, $R_{32}$ i $R_{33}$ čije se vrednosti uzimaju iz [2]. Korekcione koeficijente koji se odnose na originalnost, složenost, obimnost i značajnost $\left(E_{\text {orig }}, E_{\text {slo }}, E_{\text {obim }}, E_{\text {zna }}, I_{\text {orig }}, I_{\text {slo }}\right.$, $\left.I_{\text {obim }}, I_{z n a}, S_{\text {orig }}, S_{\text {obim }}\right)$, određuju nadležni za ocenu naučno-stručne kompetentnosti prema uputstvu datom $\mathrm{u}$ [1]. $\mathrm{U}$ datim formulama sa $k$ je označen ukupni broj ovih koeficijenata $\mathrm{u}$ formuli. Skraćenica RRT odnosi se na rukovodioca radnog tima, a RT je skraćenica za radni tim.

\section{Zaključak}

Izloženi postupak podele koeficijenta naučno-stručne kompetentnosti učesnicima na zadatku vrlo je jednostavan u idejnom smislu. Međutim, ako je broj učesnika veći, a to je u praksi najčešći slučaj, određivanje dela koeficijenta kompetentnosti za svakog od učesnika nije baš tako jednostavno zbog potrebnog izvršavanja većeg broja aritmetičkih operacija. Ova nepogodnost u izračunavanju može se prevazići izradom jednostavnog računarskog programa i pomoću računara vršiti ova izračunavanja.

Opisani postupak podele koeficijenta naučno-stručne kompetentnosti može se primeniti i na podele bilo koje celine, kada se ta celina, iz nekih razloga, ne deli na podjednake delove, već svakom delu odgovara neki rang od kojeg zavisi veličina tog dela od posmatrane celine.

Prilikom dodele vrednosti ranga ne može se u potpunosti isključiti subjektivni faktor, pa će ovakva podela od strane pojedinaca biti prihvaćena kao manje ili više nepravedna. Međutim, to je realnost koja se mora prihvatiti sa nastojanjem da se uticaj subjektivnosti učini što manjim.

\section{Literatura:}

[1] Uputstvo za vrednovanje internih naučno-stručnih radova, Tehnički opitni centar, Beograd, 2003.

[2] Pravilnik o kriterijumima za sticanje naučnih zvanja u vojnim naučnim ustanovama, Službeni vojni list, broj 21, godina CXIX, Beograd, 10. avgust 2000. 
